\title{
冗長マニピュレータのオンライン制御の為の 逆キネマティクスの高速数值解法
}

\author{
学生員 高 橋 太 郎 (棤洪国立大学) \\ 正員 河 村 篤 男 (横洪国立大学)
}

\author{
Low Cost Numerical Calculation Method for \\ On-line Inverse Kinematics of Redundant Manipulators \\ Taro Takahashi, Student-member Atsuo Kawamura, Member (Yokohama National University)
}

\begin{abstract}
A large calculation cost is required to solve the inverse kinematics problem by the numerical iterative method ( i.e. Newton-Raphson method) if the dimension of the Jacobian matrix becomes large. In this paper a new high speed numerical calculation method (SMJM method : Simply Modified Jacobian Matrix method) to solve the inverse kinematics of non-redundant manipulators and redundant manipulators are proposed. The calculation time is decreased, by replacing some elements of the Jacobian matrix with zeroes. The Monte Carlo method had been used to verify the advantage of the proposed SMJM method for the six links non-redundant manipulator and the four links redundant manipulator.
\end{abstract}

キーワード：マニピュレータ、逆キネマティクス、オンライン制御、ヤコビ行列

\section{1.はじめに}

通常、マニピュレータを制御する際の逆キネマ ティクス問題はオフラインで行わ机ることが多い。 しかし 2 足歩行ロボットなどのように環境に応じ た軌道計画を行う場合には逆キネマティクスをオ ンラインで解く必要がある。また、ロボットマニ ヒュレータの構造が複雑になると解析的な手法で は解が得られないので数值的解法を用いる必要が ある。このとき、マニビュレータの関節が多い場 合、大きな次元のヤコビ行列の逆行列を求める必 要があり、長い計算時間が必要となる。そこで、本 稿ではロボットマニピュレータのための逆キネマ ティクスの高速数值解法を提案する。

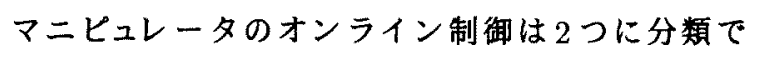
きる。

一つ目の手法はニュートンラプソン法による綝 り返し演算であり、この手法においてはヤコヒ行 列の逆行列が必要になる。圥長マニピュレータで は、疑似逆行列を用いる手法などのいくつかの手 法が提案されている(1)。しかし、関節の数が多く なるとヤコヒ行列の次数も大きくなり、その結果 オンラインの制御にとって非常に長い計算時間が 必要となる。
一方、逆ヤコヒ行列を用いない手法も提案され ている(2) (3) (4) (5)。この手法では、ヤコビ行列の 転置行列によってデカルト座標系における力が関 節座標系におけるトルクに变換され、閉ループ制 御系が設計される。この手法では、計算時間は減 少させることができるものの、ロボットマニヒュ レータにおける制御ゲインがトライアンドエラー によって決定され、応答時間が短くならない(3)。

提案する SMJM 法 (Simply Modified Jacobian Matrix method) では、ヤコビ行列の一部の成分を0に 置き換えることにより、計算時間を減少させるこ とが出来る非常にシンプルなアルゴリスムである。 この SMJM 法を 4 軸て長マニピュレータ及び 6 軸マ ニピュレータに適用し、シミュレーションを行なっ た。また、通常のニュートンラプソン法と SMJM 法の計算コストを比較するためのモンテカルロシ ミュレーションによって、提案する手法の計算量が 従来の手法に比べて少なくなることが示された。

2. 提案する SMJM 法 (Simply Modified Jacobian Matrix method)

関節角度座標系における関節角度変数 $\boldsymbol{q}$ とデカ ルト座標系における手先位置変数 $r$ の関係を式 (1) で表すと、ニュートンラプソンン法による逆キネ 


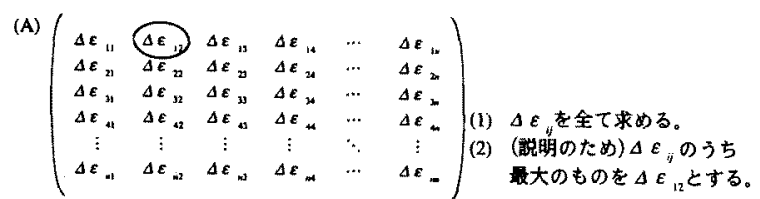

(B)

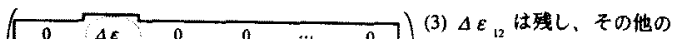

\begin{tabular}{cccccc|c}
0 & $\Delta \varepsilon_{13}$ & 0 & 0 & $\cdots$ & 0 \\
\cline { 2 - 3 } & $\Delta \varepsilon$ & $\Delta \varepsilon$ & $\cdots$ & $\Delta \varepsilon$
\end{tabular} $\begin{array}{r}\Delta \varepsilon \\
1 \text { 行の成分、2列の成分 }\end{array}$

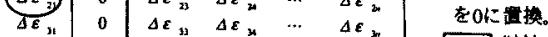

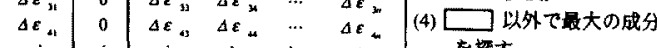

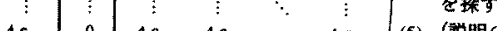

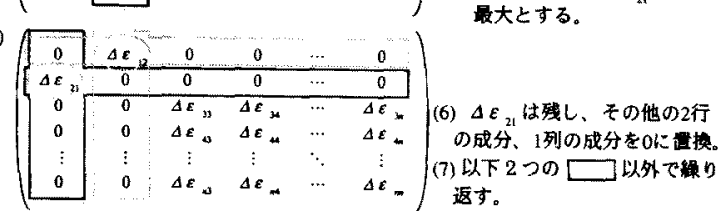

図 10 への置換法

Fig. 1. Method of Replacing with 0

マティクスでは、ヤコビ行列 $\boldsymbol{J}$ の逆行列を用いた 式 (3)の綝り返し計算によって目標とする先端の位 置や姿势 $r_{r e f}$ を実現する関節角度 $q$ が求まる。

$$
\begin{aligned}
\boldsymbol{r} & =\boldsymbol{f}(\boldsymbol{q}) \ldots \ldots \ldots \\
\dot{\boldsymbol{r}} & =\boldsymbol{J} \dot{\boldsymbol{q}} \ldots \ldots \ldots \\
\boldsymbol{q}_{i+1} & =\boldsymbol{q}_{\boldsymbol{i}}+\boldsymbol{J}^{-1}\left(\boldsymbol{r}_{\text {ref }}-\boldsymbol{r}_{i}\right)
\end{aligned}
$$

提案するSMJM 法では、計算量を減らすためにヤ コヒ行列 $J$ の代りにSMJ 行列 $J_{m o d}$ が用いられる。

\section{$\langle 2 \cdot 1\rangle \mathrm{SMJ}$ 行列}

ヤコビ行列において、各行各列において0でな い成分を1つずつ残し、それ以外の成分を0に置 換して SMJ 行列 $J_{\text {mod }}$ をつくる。例えば $j_{11}, j_{23}, j_{32}$ を残し、それ以外の成分を0に置換するとすると、 変形ヤコヒ行列の逆行列は式(4)となる。

$$
J_{m o d}{ }^{-1}=\left(\begin{array}{ccc}
j_{11} & 0 & 0 \\
0 & 0 & j_{23} \\
0 & j_{32} & 0
\end{array}\right)^{-1}=\left(\begin{array}{ccc}
\frac{1}{j_{11}} & 0 & 0 \\
0 & 0 & \frac{1}{j_{32}} \\
0 & \frac{1}{j_{23}} & 0
\end{array}\right)
$$

すなわち各成分は、式(5)で表される。

$$
j_{\text {modij }}{ }^{-1}= \begin{cases}\frac{1}{j_{j i}} & \left(\boldsymbol{J}_{\text {mod }} \text { で残された成分の } i j\right) \\ 0 & (\text { それ以外の } i j)\end{cases}
$$

マニヒュレータが壳長自由度を有する時、ヤコ と行列は正方行列でないので逆行列は存在し ないが、疑似逆行列 $J^{\dagger}$ に相当する行列 $J_{m o d}^{\dagger}=$ $J_{m o d}{ }^{T}\left(J_{m o d} J_{m o d}\right)^{-1}$ を求めることができ、その成 分は次式の様になる。

$$
j_{\bmod _{i j}}^{\dagger}= \begin{cases}\frac{j_{\bmod j i}}{\sum_{k} j_{\bmod j k}{ }^{2}} & \left(\boldsymbol{J}_{\bmod } \text { で残された成分の } i j\right) \\ 0 & (\text { それ以外の } i j)\end{cases}
$$

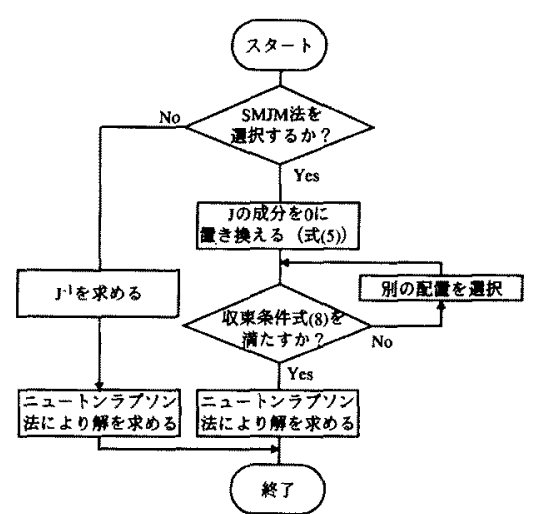

図2 SMJM 法の流れ

Fig. 2. Flow of SMJM Method

ここで $\sum_{k}$ は $J_{m o d}$ の $i$ 行において残された全ての 成分のjによる項の和である。

\section{〈2.2〉 SMJM 法}

ヤコビ行列 $J$ の一部の成分を 0 に置換すること によって、求まる解に誤差が生じる。この誤差が増 大することを防ぐため、次のアルゴリスムによっ て0に置換する成分を決定する。

それそれの成分について $\Delta \varepsilon_{i j}(i, j=1,2, \cdots, n)$ を式(7)の様に定義する。

$$
\Delta \varepsilon_{i j} \triangleq\left|\left(\sum_{k=1, k \neq j}^{n} j_{i k} \dot{q}_{k}\right)^{2}-\left(\sum_{k=1}^{n} j_{i k} \dot{q}_{k}\right)^{2}\right|
$$

$\max _{i, j}\left\{\Delta \varepsilon_{i j}\right\}$ を満足する成分に第 1 番目の優先順 位を与え、 $i$ 行および $j$ 列の成分のうち $i j$ 成分以外 を0に置き換える(図 1)。次に、同じ操作が残りの 行および列の成分に対して行なわれる。すなわち、 $i$ 行およひ $j$ 列以外の成分の中で $\max _{i, j}\left\{\Delta \varepsilon_{i j}\right\}$ を満 足する成分に第 2 番目の優先順位を与え、その成 分以外の成分を0に固き換える。この時本手法で は、関節角速度 $\dot{q} か ゙$ 必要となる。この操作を綝り 返し、各行各列に1つずつの成分が残るようにす る。本手法の䛩差 err は式 $(8)$ にり評価される。

$$
e r r=r_{r e f}-r_{i} \leq \lambda
$$

式 (8)が満足されない場合には、SMJ 行列は不十 分であると判断し、次のように成分を選択し直す。 すなわち、1つ前の段階へ戻り、最後に優先順位を 与えた成分 $\left(\Delta \varepsilon_{i j}\right.$ が最大だった成分)を元に戻し、2 番目に大きい $\Delta \varepsilon_{i j}$ をとる成分を残し、それ以外の 成分を０に置き換える。

式 (8)の条件を満足した場合、これが最終的な SMJヤコビ行列となる。式 $(8)$ の条件を満足しない 


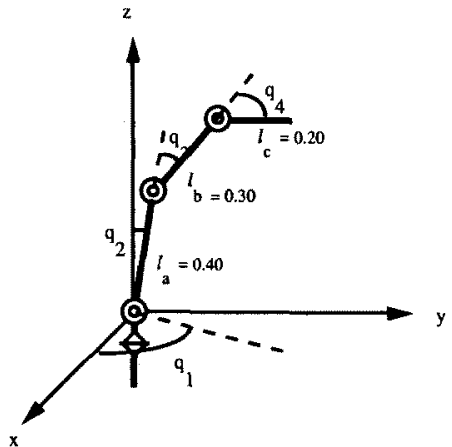

図 34 軸圥長マニピュレータ

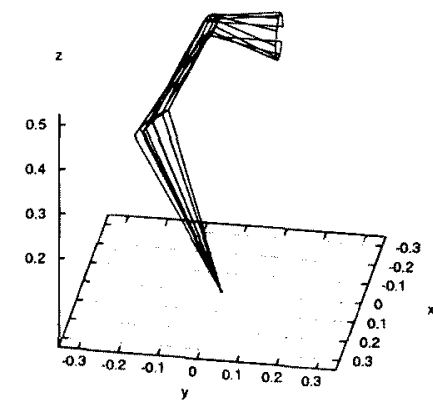

図 4 計算例 (4 軸)

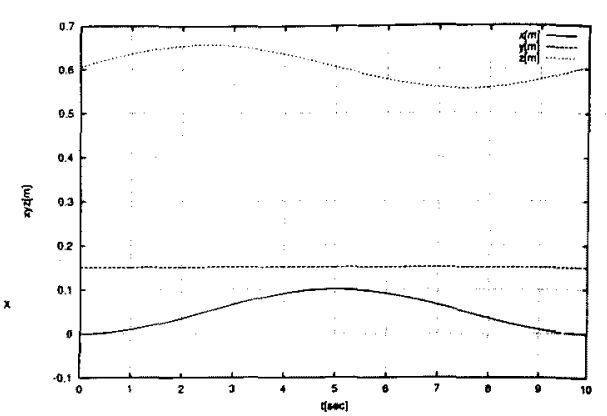

国 5 手先位置座標 (4 軸)

Fig. 3. Redundant Manipulator Fig. 4. Simulation Result (4 Link) Fig. 5. End Point Position (4 Link)

場合は、3番目に大きい $\Delta \varepsilon_{i j}$ をとる成分を選択す る。これらの操作が再帰的に行なわれる(図 2)。

\section{〈2・3〉證差が增大する問題に対する対策}

$\mathrm{SMJ}$ 行列を用いた逆キネマティクスでは、まれ に誤差が徐々に大きくなり最終的に発散すること があるので、次の操作（のいずれか）を行う。

- 数回に一度、定期的に通常のヤコヒヒ行列を用 いて解を求める。これは、通常のヤコビ行列 を目標軌道から外れていく解を、強制的に正 しい解に近づけるとになる。

- 生しる誤差を 3.3 節で後述する近似によってあ らかじめ求め、生じる誤差が大きくなる場合 には通常のヤコヒ行列を用いて解を求める。 これらのアルゴリスムを組み込むことにより、誤 差が增大することを防ぐことができる。(なお、可 操作度が大きい場合、すなわち特異姿勢から遠い 場合はこのょうな状態は発生しない(7)。）次節にお いて、前者の手法をを 4 軸冗長マニピュレータに適 用した例を 3.1 節 3.2 節に示す。また、後者の手法 を 6 軸非冗長マニビュレータに適用した例を 3.3 節 3.4 節に示す。

\section{3. 計篮例}

\section{〈3.1〉4郵冗長マニピュレータにおける計算例}

図3の4軸圥長マニピュレータにおいて 2 回に1 回、通常のヤコビ行列を用いて SMJM 法による逆 キネマティクスの演算を行なった。

目標軌道 $r_{r e f}$ は、平面 $y=0.15$ 上の半径 $0.05[\mathrm{~m}]$ の円軌道とし、10[sec] で一周させた。サンブリン クタイム $h$ は $0.01[\mathrm{sec}$ 、収束判断基準 $\lambda=0.001[\mathrm{~m}]$ とし、通常のニュートンラプソン法の㒭差許容値 $t o l=0.00001[\mathrm{~m}]$ とした。なお、tol 小さくすると、 はしめの SMJ 行列によって解が求まる確率が高く なる傾向がみられ、逆に入を小さくするとその確 率が低くなる傾向が見られる。シミュレーションに おいて関節角速度 $\dot{q}$ は関節角度の時間差分を用い、 SMJ 行列を用いたニュートンラプソン法の絽り返 し演算は 1 回のみ行なうものとした。

結果は図4の様になりマニピュレータは目標軌道 の円軌道を描いていることがわかる。さらに、時 間 $t$ に対し手先位置座標をプロットしたクララフが 図 5 であるが、先端が目標軌道を描いていること がわかる。なお、この時通常のニュートンラプソ ン法が選択された場合は手先位置誤差は tol 以下と なり、SMJM法が選択された場合の誤差は最大で $\lambda=0.001[\mathrm{~m}]$ 以下となり、十分実用筙囲であった。

〈3.2〉4軸涱マニピュレータのモンテカルロ法 による計萛コストの比

提案する SMJM 法では SMJ 行列の成分の組合せ を变更した回数によって計算コストが異なるため、 モンテカルロ法によるシミュレーションによって計 算コストを求め、従来の手法と計算コストを比較 した。

乱数によりランダムな 3000 通りの初期姿勢と先 端速度 $0.01[\mathrm{~m} / \mathrm{sec}]$ の直線軌道を設定し、正碓な解 が求まるまでに組合せを変更したそれそれの回数 の相対度数を求めることにより SMJM 法の計算コ ストを求めた。その際設定した姿勢は、特異姿知を 除くために可操作度 $w_{2}, w_{3}>0.00001$ の姿勢に限定 した。この可操作度は $J$ の特異値を $\sigma_{1}, \sigma_{2}, \ldots, \sigma_{m}$ として $w_{2}=\sigma_{m} / \sigma_{1}, w_{3}=\sigma_{m}$ と定義される(8)(9) (10)。また、誤差を $95 \%$ の信頼区間として定義して 区間推定を行った。なお、ここでは便宜上、速度に ついては一定としてシミュレーションを行った。 
表 1 几長マニピュレータにおける計算コスト (2回に1回、SMJ行列を選规)

Table 1. Calculation Costs of Redundant Manipulators(Select SMJ matrix Once a Twice)

\begin{tabular}{|c|c|c|}
\hline & + & $x \div$ \\
\hline Gauss-Jordan 法により签似逆行列を隶める方法 & $m^{3}+2 m^{2} n+m n$ & $m^{3}+2 m^{2} n-3 m^{2}+m$ \\
\hline 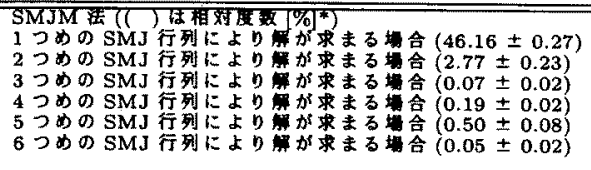 & $\begin{array}{l}3 m n-2 m+n \\
3 m n-3 m+2 n \\
3 m n-4 m+3 n \\
3 m n-5 m+4 n \\
3 m n=6 m+5 n \\
3 m n-7 m+6 n\end{array}$ & $\begin{array}{r}2 m n-m+3 n \\
2 m n-3 m+6 n \\
2 m n-5 m+9 n \\
2 m n-7 m+12 n \\
2 m n-9 m+15 n \\
2 m n-11 m+18 n\end{array}$ \\
\hline 通常の=ュートンラフンンン法 $(50.00 \pm 0.0$ & $\left(m^{3}+2 m^{2} n+m n\right)+3 m n-$ & $\left(m^{3}+2 m^{2} n-3 m^{2}+m\right)+2 m n-\ldots$ \\
\hline SMJM 法の部萛コスト & $0.5 m^{3}+m^{2} n$ & $0.5 m^{3}+m^{2} n-$ \\
\hline
\end{tabular}

表 2 非冗長マニヒュータにおける計算コスト(近似により請差を見樌もり、SMJ行列を選択)

Table 2. Calculation Costs of Non-Redundant Manipulators (Select SMJ matrix by approximation to error)

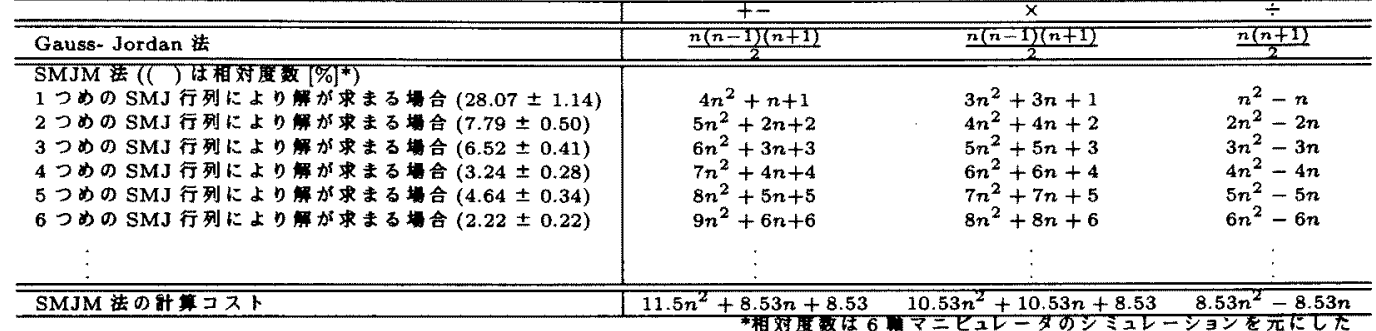

計算コストは (a) $\Delta \varepsilon_{i j}$ を求めるコスト、(b) $\Delta \varepsilon_{i j}$ の ソートコスト、(c) $J_{\text {mod }}{ }^{-1}$ を求めるコスト、(d) $J_{\text {mod }}{ }^{-1}$ に対する式(3)のコスト、に分けられる。このうち 表 1 は (a)(c)(d)のコストを示す（(b)を含めたコス トについては後で考察する)。表1において左の列 の括弧内に相対度数を示し、ヤコヒ行列が $m \times n$ 行 列であるとした各演算コストを右の唡に示す。これ らをそれそれの回数について挂け合わせ、その結 果を加え合わせることによって提案する手法の演算 コストが求められる。従来手法として Gauss-Jordan 法により疑似逆行列を用いて解を求めた場合の演 算コスト（最上段）と比較して、 $n$ および $m$ が大き くなると SMJM 法が有利であることがわかる。

〈3.3〉6軸非冗長マニピュレータにおける計臭 例生しる誤差を近似によって求めることに よってSMJ 行列を用いるかを決定する方法によっ て図6の6軸のPUMA 型マニピュレータにおいて逆 キネマティクスの演算を行った。

生しる諆差は、次の様に近似によって求めること ができる。SMJ 行列を用いてニュートンラプソン 法の綝り返し演算を 1 回行なうと、式(9)より SMJ 行列で求めた関節角度 $\boldsymbol{q}_{\text {modi }}$ が求まる。

$$
\boldsymbol{q}_{\text {modi }}=\boldsymbol{q}_{i-1}+\boldsymbol{J}_{\text {mod }}{ }^{-1}\left(\boldsymbol{r}_{r e f}-\boldsymbol{r}_{i-1}\right)
$$

式 (3)、式(9)より $J_{\text {mod }}$ を用いたニュートンラプソ ン法の演算 1 回で生じる関節角度の誤差 $q_{i}-q_{\text {modi }}$

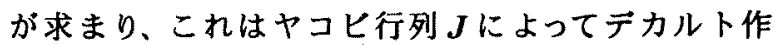
業座標系に変換することができる。

$$
\begin{aligned}
\boldsymbol{r}_{i}-\boldsymbol{r}_{m o d i} & \approx \boldsymbol{J}\left(\boldsymbol{J}^{-1}-\boldsymbol{J}_{m o d}{ }^{-1}\right)\left(\boldsymbol{r}_{r e f}-\boldsymbol{r}_{i-1}\right) \\
& =\left(\boldsymbol{I}-\boldsymbol{J} \boldsymbol{J}_{m o d}{ }^{-1}\right)\left(\boldsymbol{r}_{r e f}-\boldsymbol{r}_{i-1}\right) \cdots
\end{aligned}
$$

ここで $\boldsymbol{A}=\boldsymbol{I}-\boldsymbol{J} \boldsymbol{J}_{\bmod }{ }^{-1}$ とおく。また、通常のニュー トンラプソン法により求めた $\boldsymbol{r}_{i}$ が目標值 $\boldsymbol{r}_{r e f}$ とほ ほ等しいとすれば、

$$
\begin{aligned}
e r r_{m o d} & =\boldsymbol{r}_{r e f}-\boldsymbol{r}_{\text {modi }} \\
& \approx \boldsymbol{A}\left(\boldsymbol{r}_{\text {ref }}-\boldsymbol{r}_{i-1}\right)
\end{aligned}
$$

この式(12)は、デカルト作業座標系での目標軌道 に対する $J_{\text {mod }}$ を用いる場合の誤差を表している。

例えば、ヤコヒ行列 $J$ が $3 \times 3$ であり成分 $j_{11}, j_{23}, j_{32}$ が残されたとすると、Aは次式(13)のようになる。

$$
\boldsymbol{A}=\left(\begin{array}{ccc}
0 & \frac{j_{13}}{j_{23}} & \frac{j_{12}}{j_{32}} \\
j_{21} & 0 & \frac{j_{22}}{j_{11}} \\
\frac{j_{31}}{j_{32}} & \frac{j_{33}}{j_{11}} & 0
\end{array}\right)
$$

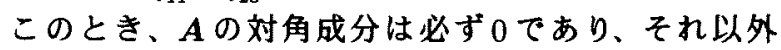
の成分については $\boldsymbol{A}$ の $i$ 列成分の分母は $J_{m o d}$ の $i$ 行において残された成分となる。また、 $\boldsymbol{A}$ の $i j$ 成 分の分子は、その $i j$ のうち $i$ をそのまま、 $j$ は分母 と同し $j$ を用いた $J_{m o d}$ の $i j$ 成分となる。実際の計 算においては、行列 $\boldsymbol{A}$ の各成分には、この規則性 により簡単に求めることができる。 


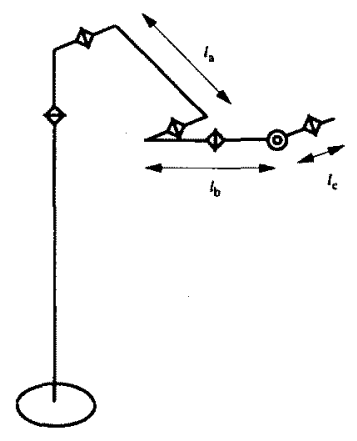

図66軸マニピュレータ

Fig. 6. Six Links Manipulator

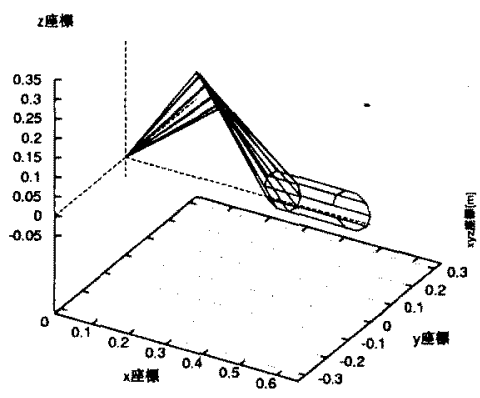

図 7 計算例 (6 軸)

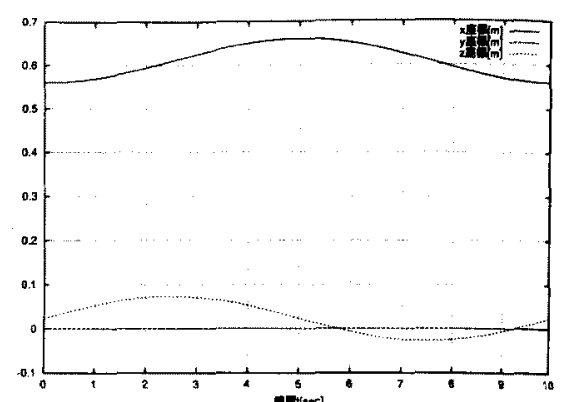

図 8 手先位置座標 (6 軸)

Fig. 7. Simulation Result (6 Link) Fig. 8. End Point Position (6 Link)

結果は、図7の様になり、先端姿勢を一定に保ち ながら目標としていた円を描いていることが分か る。さらに、時間 $t$ に対し手先位置座標をプロット したものが図8であるが、手先奻果器が目標軌道 を描いていることがわかる。

(3.4〉6軸非冗長マニビュレータのモンテカルロ 法による計萛コストの比較

3.2 と同様の方法により、6 軸マニピュレータにお けるモンテカルロシミュレーションにより従来の 手法と計算コストを比較した。ヤコビ行列が $n \times n$ 行列の場合のSMJM 法の計算コストを表 2 に示す。 なお、この表には式(12)の演算量も含まれる。本 シミュレーションでは $n=6$ であるが、 $n$ が大きく なると SMJM 法が有利であることがわかる。

〈3.5〉実用上の計算コスト 本手法は実用上 は次の $(\mathrm{a})(\mathrm{b})(\mathrm{c})$ の 3 通りの方法によりさらに演算 量を隇らすことができる。(a)いくつかのSMJ行列 によっても正確な解が求まらない場合、通常のヤ コヒ行列によって解を求める。また、(b) 式 (7) の代 りに、計算量の少ない $\Delta \varepsilon_{i j} \triangleq\left|j_{i j} \dot{q}_{j}\right|$ を用いる。こ の变更は SMJ 行列の選択に影雪し相対度数の違い となって現れるが、最終的な解の誤差の最大值は 収束判定基準入によって保証されるので变化しな い。さらに、(c) $\Delta \varepsilon_{i j}$ のソーティンクは、図 9 のよう に、2つの成分をセットにして順次比較し、最大の 成分を見つける。この最大の成分を残し、その行 および列の成分を $0 に し た$ 後、残りの成分の中か ら同様の方法で最大の成分を選ぶ。この際にはそ れ以前に利用したセットは再び利用する。

例えばヤコヒ行列が $6 \times 6$ 行列であるとすると、 式(14)より53回の比較により SMJ 行列の成分を決 定することができる。ここで2つ目の括弧の中の $-10-5$ などは、以前に利用したセットを再利用す るための減少分であり、この部分は組合わせによ
(A)

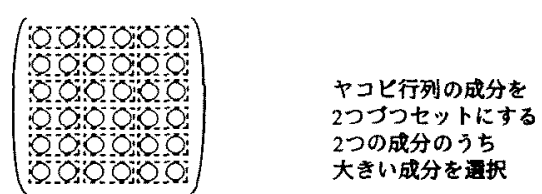

(B) :ópooróno $\begin{array}{lll}0 & 0 \\ 0 & 0 & 0\end{array}$

(C)

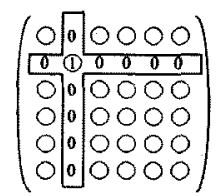

最大の成分のおる行と
列以外の成分において
同畨の埙作を䋖り返し 行”

図 9 改良した置換法

Fig. 9. Improved Method of Replacing

り多少增隇する。

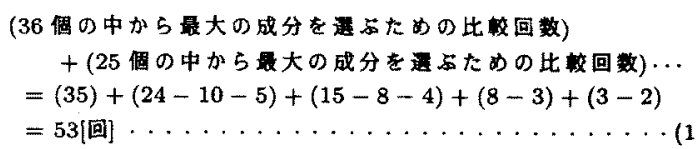

2 つ目のSMJM行列により解が求まる場合は、 最後に決定した成分を変更するのみでよいから $53+1=54$ [回] が 2 回までSMJ 行列を変更する場合 の比較回数である。なお、マニピュレータの姿勢变 化が微少であるとして式 (12) の計算は毎回は行わ ないものとする。その後通常のニュートンラプソ ン法を行う場合の計算量も含め、表にまとめると 表 3 のようになる。さらに、SMJM 法を複数回用い る場合の計算コストの变化は図 10 の様になり6回 程度が最適であることがわかる。 


\section{4. 必要なサンブリング周期}

本手法では終了するまでの時間が変化するので、 制御のサンプリンク周期は最長の場合に合わせる 必要があるが、図 11 の様にサンプリンク周期は長 く設定する必要があるものの、総合的には必要な 時間は従来の手法よりも短くなる。よってこれら の残存時間を、例えば経路生成や環境のモテリン ク等の様なコントローラの上位の部分によって利 用することにより本手法のメリットを生かすこと ができる。

表 35 回までSMJM 法を用いる場合の計 算回数の比較 (ヤコヒ行列が $6 \times 6$ の場合)

Table 3. Each Operation Number when SMJ Matrix was Changed until Five Times (Jacobian is $6 \times 6$ )

\begin{tabular}{|c|c|c|c|c|}
\hline & +- & $x \div$ & 比呅 & 合许 \\
\hline "Gauss-Jordan 法による场合 & 105 & 126 & & 231 \\
\hline 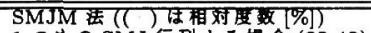 & & & & \\
\hline 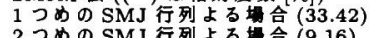 & 12 & 42 & 53 & 107 \\
\hline 2 つめのSMJ 行烈よる & 24 & 54 & 54 & 137 \\
\hline 4 つめの SMJ 行列よる堨合 $(7.33)$ & 30 & $\begin{array}{l}54 \\
60\end{array}$ & $\begin{array}{l}59 \\
60\end{array}$ & 150 \\
\hline 5 つめの SMJ 行列よる场合 $(3.88)$ & 36 & 66 & 64 & 166 \\
\hline その後 Gauss-Jordan 法 (39.26) & 141 & 192 & 64 & 397 \\
\hline SMJM 法の期傅面 & $\overline{66.3}$ & 104.5 & $\overline{58.8}$ & $\overline{229.6}$ \\
\hline
\end{tabular}

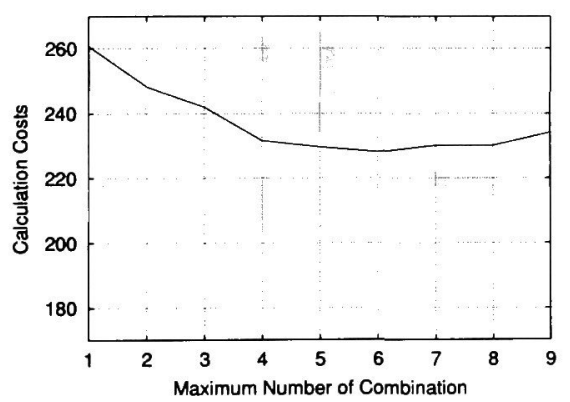

図 10 計算回数の変化 (6 軸の場合)

Fig. 10. Number of Calculation (6 axis)
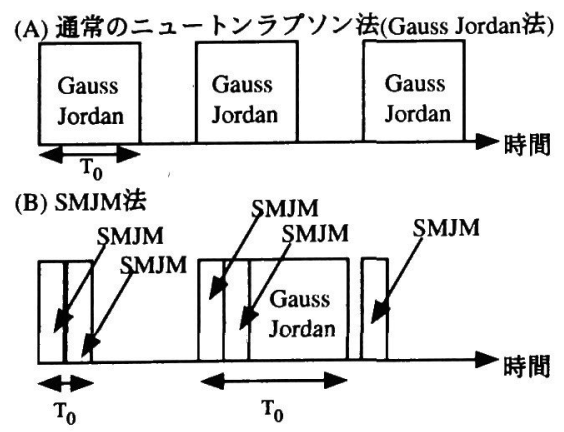

図 11 計算時間

Fig. 11. Calculation Time

\section{5. まとめ}

本稿では、ヤコヒ行列の一部の成分を 0 に置換 することにより短い計算時間によって解くことの できる逆キネマティクスの数值解法解法、SMJM 法を提案し、モンテカルロシミュレーションにより 演算コストが通常の方法より小さくなることを示 した。本手法を適用することにより、朵長マニピュ レータのオンライン制御がより容易になる。

最後に本研究の一部は文部省科学研究費補助金 によって行われたことを付記する。

(平成 12 年 2 月 1 日受付、平成 12 年 10 月 11 日再受付)

$$
\text { 文 献 }
$$

(1) D.L. Pieper: "The Kinematics of Manipulators under Computer Control", Ph. D. Thesis, Stanford University (1968)

(2) 花房、吉川、中村: “関節形ロボットアームの㫕長性の解析 とその得先順位を有する作業への応用”, 計澌自動制御学 会論文菓, vol. 19 , No. $5,421 / 426$ (1983)

(3) 竹垣、有本: “マニヒュレータの作業座標フィードバック制 御”計湘自動制御学会論文集, vol. 17, No. $5,582 / 588$ (1981)

（4）井上: “咒長マニヒュレータの渐近的制御についで計測自 動制御学会論文集, vol. 26, No. 3, 339/343 (1990)

(5) 播磨、川口、中谷、二宮: “新しいスライティンクモードを 用いた宇宙用圥長マニヒュレータの制御”，日本ロボット学 会誌, vol. 9 , No. $7,821 / 829$ (1991)

(6) 高橋、河村: “非冗長マニヒュレータにおける逆キネマティ クスの高速数値解法の提案”, 電気学会論文誌 D, Vol.118-D No.12, pp.1454-1455 (1998)

（7）高橋、河村: “逆キネマティクスにおける逆ヤコヒ行列の简 易計算法の提案”, 電気学会産業計测制御研究会, IIC-99-15, pp.95-100 (1999)

(8) T. Yoshikawa: "Analysis and Control of Robot Manipulators with Redundancy", Robotics Research, The First International Symposium, eds. M. Brady and R.Paul, MIT Press, cambridge, Mass. pp.735-747(1984)

(9) J.K. Salisbury, J.J. Craig: "Articulated Hands, Force Control and Kinematic Issues", Int. J. Robotics Research, 1, 1, pp.4-17 (1982)

(10) C.A. Klein : "Use of Redundancy in the Design of Robotic System, Robotics Research, The Second International Symposium, eds. H. Hanafusa and H. Inoue, MIT Press, Cambridge, Mass., pp.207-214 (1985)

量太郎 (学生員) 1973 年 9 月 10 日生。1997年 3 月

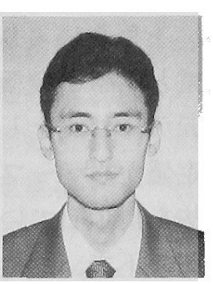
横浜国立大学龟子情報工学科卒業、同年 4 月同大学院工学研究科博士課程入学。同年 4 月より日本学術振興会特别研究員。2 足 步行ロボット及びマニピュレータのオンラ イン制御に関する研究に従事。電気学会、 ロボット学会、IEEE 学生会員。現在、横浜 国立大学大学院工学研究科博士課程後期在 学中。

河村第男 (正員) 1953 年 12 月 17 日生。1981 年 3 月 東京大学大学院工学系研究科電気工学博 土課程修了。現在、横浜国立大学工学部電 子情報工学科教授。主として、パワーエレ クトロニクス、ロボティクス、ティジタル 制御などの研究に従事。工学博士。1988年 IEEE/IAS 論文誌論文賞、1996 年電気学会 諭文賞授賞。IEEE、車子情報通信学会、口 ボット学会、計测自動制御学会等会員。 